\title{
Predictors for conversion in laparoscopic splenectomy: A prospective randomized study
}

\author{
Moemen Abo Shloaa, MD; Gamal El Moaled, MD; Mahmoud Saad, MD; \\ Mostafa foaad, MD; Haitham El Maleh, MRCS, MSC
}

\author{
Department of General Surgery, Ain Shams University, Cairo, Egypt.
}

\begin{abstract}
Background \& objectives: Laparoscopic splenectomy had become the golden standard for elective splenectomy, as it is feasible, safe and provides many advantages to the patients in comparison to open splenectomy, and the growing experience and the advances in equipment had made it feasible in situations that were thought to be contraindications in the past. However, some cases still require conversion to an open procedure. Identifying predictive factors for conversion carries crucial benefits for patients and health care providers.

Methods: 24 patients underwent elective laparoscopic splenectomy for different indications in our hospital between January 2008 and February 2010. Patients' data whether preoperative, operative or postoperative were collected and assessed statistically to identify the risk factors for conversion to open splenectomy.

Results: The study included 24 patients (13 ITP, 5 spherocytosis, 4 chronic lymphocytic leukemia (CLL) and 2 Lymphoma patients). The rate of conversion was $16.7 \%$ (4 patients). The mean operative time was $116.5 \pm 23.9$ minutes; the mean estimated intraoperative blood loss was $286.5 \pm 165.7 \mathrm{ml}$. The mean period until passage of flatus was $2 \pm 1.1$ days, patients resumed oral food intake in $3.2 \pm 1.4$ days and were discharged from the hospital in $4.6 \pm 1.9$ days. 4 patients had post operative complications in their hospital stay, and one needed reexploration. The significant risk factors for conversion in the study was diagnosis, ASA score 3, presence of technical difficulty, preoperative platelet count $<71 \times 10^{3} \mathrm{~cm}^{3}$, splenic longitudinal axis length $>17 \mathrm{~cm}$ and intraoperative blood loss $>500 \mathrm{ml}$.

Conclusions: Proper analysis of all factors affecting successful completion of laparoscopic splenectomy will lead to better implementation of the procedure in context with patient's needs and the technical expertise of the surgical team, both leading to better outcomes. This will also help to address the areas of potential improvements to be implemented.
\end{abstract}

\section{Introduction:}

Splenectomy is performed either as causal or symptomatic therapy for numerous indications. Formerly, open splenectomy represented the traditional for patients with different indications of splenectomy. ${ }^{1}$ The first successful laparoscopic splenectomy was reported by Delaitre and Maignien in 1991,2 and since then, the procedure had been adopted as the standard technique for most indications for splenectomy throughout the world. ${ }^{3}$ The wide acceptance of laparoscopic splenectomy is based on the benefits it offers compared to open splenectomy, which include decreased analgesia use, earlier initiation of oral diet, decreased length of stay, and fewer complications, together with comparable clinical outcomes. ${ }^{4}$ Moreover, the growing experience and the advances in equipment had made this approach feasible in situations that were thought to be contraindications in the past. ${ }^{3}$

Conversion from laparoscopic splenectomy to open surgery is occasionally experienced; reported conversion rates range from $0 \%$ to $19 \%$. Many factors affect the rates of conversion, some of them are related to the indication, others to technical aspects, and 
other factors are related to the patient's condition. Several studies had tried to address the factors leading to conversion. Intraoperative bleeding, difficulty in manipulating the spleen due to size or densly adherent adjacent structures were reported to be the most common causes of conversion..$^{5-7}$ Also, the presence of giant spleens, and portal hypertension were linked to high conversion rates. ${ }^{3,8}$ Moreover, with laparoscopic splenectomy being an advanced procedure, the level of experience of the surgeon has a profound impact on conversion rates. ${ }^{9}$

This study aims to identify the risk factors that prevent the succeful completion of laparoscopic splenectomy.

\section{Patients and methods:}

The study was carried out in Ain Shams University Hospitals during the period between January 2008 and February 2010. Patients who were referred to our surgical team with indications of splenectomy during that period were prepared for elective laparoscopic splenectomy. 24 patients were enrolled in the study.

Preoperative preparation of all patients included vaccinations with polyvalent pneumococcal, polyvalent meningococcal, and Haemophilus influenza type $b$ conjugate vaccines, and preoperative antibiotics. Other preoperative measures were individualized according to each patient condition. Transfusion of blood products, such as platelets, packed red blood cells, or gamma globulin, was performed according to the plan of the referring hematologist, or anesthesiologist. Routine preoperative imaging (US and CT) to determine splenic size or the presence of accessory splenic tissue was performed. Prophylactic intraoperative platelet transfusions were performed in all patients with platelet counts of less than $55 \times 10^{3} / \mathrm{cm}^{3}$.

The procedure is performed with the patient under general anesthesia with endotracheal entubation. A nasogastric tube is inserted to decompress the stomach and a Foley's catheter is inserted to the bladder. The patient is put in the supine position with legs apart and a $20^{\circ}$ head-up tilt (reversed Trendelenburg position). The surgeon operates in the "French" position (between the patient's legs) with the camera assistant on his left and the second assistant to the right. A $10 \mathrm{~mm}$ cannula is inserted at the level of the umbilicus using the open technique and carbon dioxide pneumoperitoneum is induced. Thorough exploration of the abdomen, pelvis, and omentum for accessory spleens using a $30^{\circ}$ angled scope is carried out at first. Then, four more trocars are inserted under direct vision, placed in a half-circle facing the left upper quadrant as shown in the Figure(1).

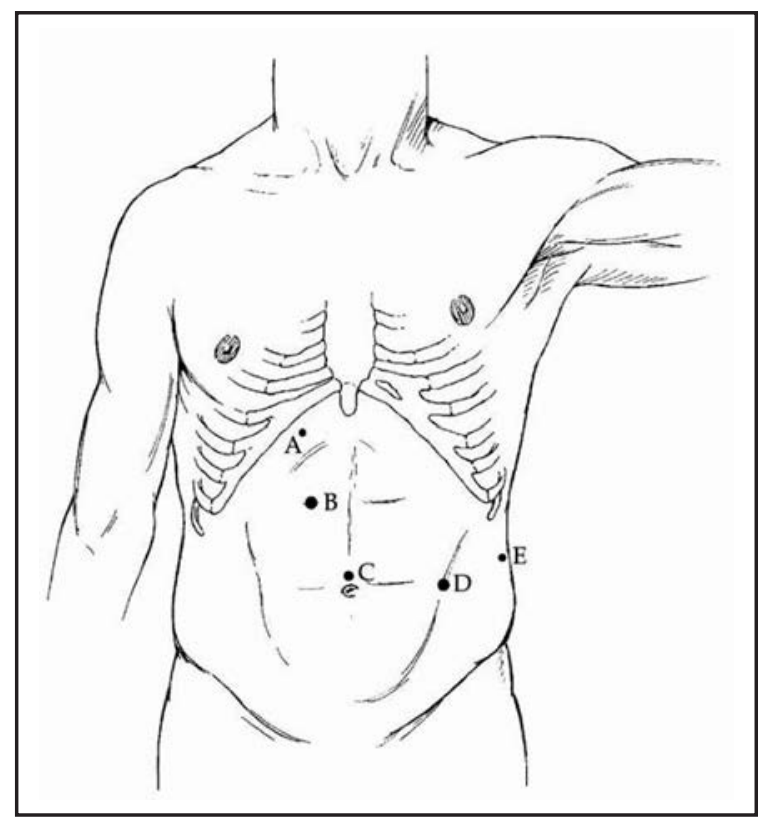

Figure (1): Drawing of the positioning of the trocars A and E: 5-mm trocars; $B: 10-m m$ trocar; C: camera; D: 10- or 12-mm trocar. 
The table is then tilted $30^{\circ}$ to the right so that the viscera gravitate toward the right lower quadrant, thus exposing the spleen. The left hepatic lobe is retracted with a liver retractor through the right lateral $5 \mathrm{~mm}$ trocar site. The stomach is retracted medially through the left 5 -mm trocar to expose the spleen after the omentum has been displaced inferiorly. Then the phrenicocolic and the splenocolic ligaments are incised near the lower pole using the Ligasure through the left 10 -mm port. The lower pole of the spleen is gently lifted by a

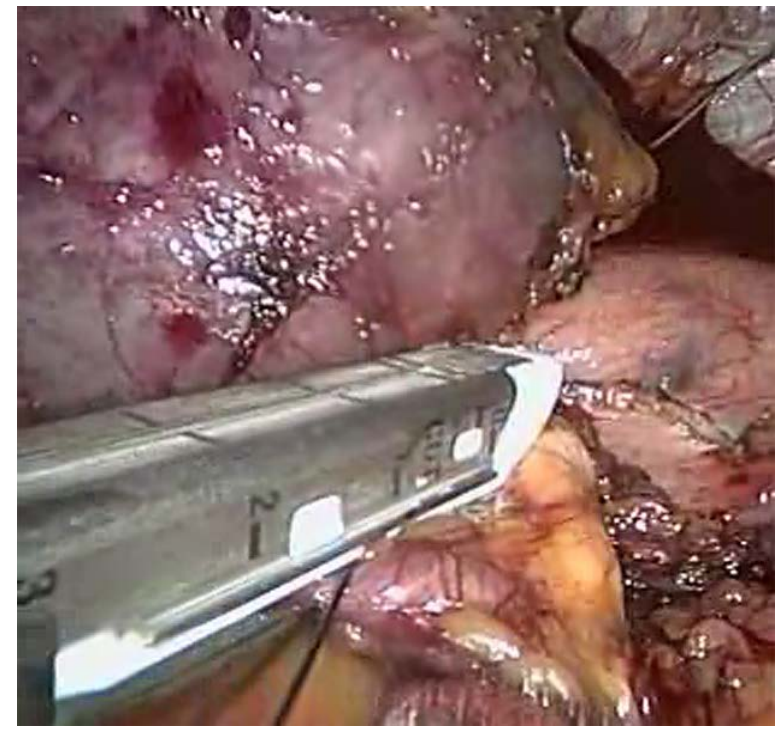

closed instrument without grasping which is introduced through a 5-mm port to expose the splenic hilum and the tail of the pancreas. Using the lateral tilt, we can safely create a window above the tail of the pancreas to permit the application of a stapling device and to control all hilar vessels. In our case we used an Endo-GIA with a vascular cartridge to transect the hilum as shown in Figure(2). 2 or 3 firings are usually needed. After control of the hilar vessels, the short gastric vessels are then divided using the Ligasure.

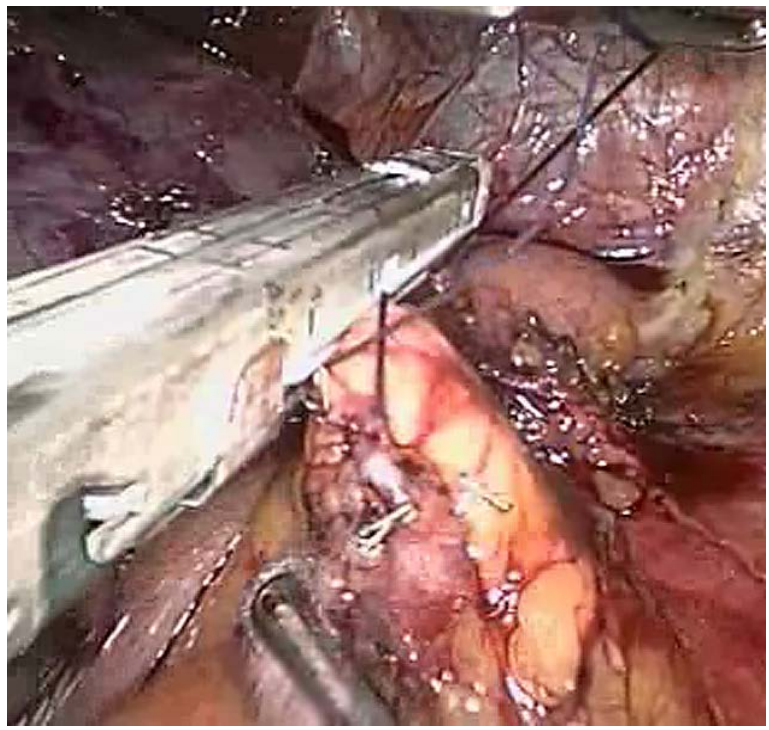

Figure (2): Application of Endo-GIA to the hilum.

After that, proper hemostasis is ensured. The specimen is then inserted into a plastic bag, and the spleen is morcellated using a long forceps and the bag is extracted through enlarging of the $12 \mathrm{~mm}$ port site. After reestablishing of pneumoperitoneum, fast reexploration is done to ensure proper hemostasis. A redivac is advanced through the left trocar site and placed in the left subphrenic space. The operation is completed by closure of all trocar ports. In patients whom the attempt for vascular control of the pedicle using the endo GIA is unsuccessful, the decision for conversion is taken to complete the procedure. When conversion is needed, a standard midline incision is used for exploration.

Postoperatively, the patients are observed for vital data, return of bowel functions and wound complications. The patients were discharged after return of normal bowel functions, drain removed and any complication ruled out.
Perioperative parameters were assessed, including patient age and sex, surgical indication for splenectomy, American society of Anesthesiology (ASA) score, other comorbidities, size of the longitudinal access of the spleen, preoperative hemoglobin and platelet count and body mass index. Operative data were assessed including operative time in minutes, presence of technical difficulty, estimated blood loss, requirement for blood product transfusion, spleen specimen weight and the need for conversion to open splenectomy. Postoperative data was assessed including period of ileus, time to oral intake, length of hospital stay, the need for reoperation and postoperative morbidity or mortality. Additional information was obtained by direct patient interview or review of medical records when necessary. 
Converted patients and completed ones were compared for univariate analyses of risk factors for conversion using the independent sample t-test (for continuous variables, like age) and chi-square test for categorical variables (such as gender). Factors for which the $\mathrm{P}$ value obtained on univariate analysis was less than 0.05 were used in subsequent multivariate analysis with a stepwise logistic regression model. Stepwise multivariate logistic regression was performed to determine which combination of variables significantly discriminated the two groups. Odds ratios and their $95 \%$ confidence intervals were calculated from logistic regression. Significance levels of 0.05 and two-tailed tests were used in hypothesis tests.
ROC curve was used to calculate the cutoff values for significant continuous variables. All calculations were done using SPSS version 17 statistical software.

The study aimed to identify the risk factors for conversion to open splenectomy.

\section{Results:}

This study included 24 patients. The indication for splenectomy was thrombocytopenia in all patients. The cause of thrombocytopenia was ITP in $13(54.2 \%)$ patients, spherocytosis in $5(20.8 \%)$ patients, chronic lymphocytic leukemia (CLL) in 4 (16.7\%) patients and lymphoma in $2(8.3 \%)$ patients as shown in Table(1).

Table (1): Showing the indication of splenectomy in the study group.

\begin{tabular}{|c|c|c|}
\hline Indication & Frequency & Percent \\
\hline ITP & 13 & 54.2 \\
\hline Spherocytosis & 5 & 20.8 \\
\hline CLL & 4 & 16.7 \\
\hline Lymphoma & 2 & 8.3 \\
\hline Total & 24 & 100.0 \\
\hline
\end{tabular}

The study group consisted of $10(41.7 \%)$ males and $14(58.3 \%)$ females. The mean age of the patients was $26.5 \pm 8.9$ years with range from 16-48 years. 2 patients had associated comorbidities (diabetes mellitus). 22 patients $(91.7 \%)$ had ASA score of 2 and the remaining 2 patients $(8.3 \%)$ had ASA score of 3 . The patients had mean BMI of $24 \pm 1.9 \mathrm{~kg} / \mathrm{m}^{2}$ with a range between 21 and 28 . The longitudinal splenic dimension was $16 \pm 2.9 \mathrm{~cm}$ with range from 12 to $22 \mathrm{~cm}$. The mean preoperative hemoglobin and platelet count were 12.2 \pm 1.2 $\mathrm{gm} / \mathrm{dl}$ and $63.6 \pm 8.5 \times 10^{3} \mathrm{~cm}^{3}$ receptively. The preoperative data are shown in Tables $(2,3)$.

Table (2): Preoperative data.

\begin{tabular}{|c|c|c|c|c|c|}
\hline Variable & Age & BMI & $\begin{array}{c}\text { Splenic } \\
\text { longitudinal axis } \\
\text { length }(\mathrm{cm})\end{array}$ & Preoperative Hb & $\begin{array}{c}\text { Preoperative } \\
\text { Platelet Count } \\
\left(\times 10^{3}\right)\end{array}$ \\
\hline Mean & 26.5 & 24 & 16 & 12.2 & 63.6 \\
\hline Std. deviation & 8.9 & 1.9 & 2.9 & 1.2 & 8.5 \\
\hline Minimum & 16 & 21 & 12 & 10 & 48 \\
\hline Maximum & 48 & 28 & 22 & 15 & 80 \\
\hline
\end{tabular}

Table (3): Preoperative data.

\begin{tabular}{|c|c|c|c|c|c|c|}
\hline \multirow{2}{*}{ Variable } & \multicolumn{2}{|c|}{ Gender } & \multicolumn{2}{c|}{ Comorbidity } & \multicolumn{2}{c|}{ ASA score } \\
\cline { 2 - 7 } & Male & Female & None & DM & 2 & 3 \\
\hline Frequency & 10 & 14 & 22 & 2 & 2 & 22 \\
Percent & 41.7 & 58.3 & 91.7 & 8.3 & 8.3 & 91.7 \\
\hline
\end{tabular}


Laparoscopic splenectomy was done for all patients. The operation was successfully completed laparoscopically (no conversion) in 20 patients $(83.3 \%)$. The conversion was done in the remaining 4 cases $(16.7 \%)$ due to bleeding which couldn't be controlled. The mean operative time was $116.5 \pm 23.9$ minutes. The mean estimated intraoperative blood loss was $286.5 \pm 165.7 \mathrm{ml}$. Technical difficulties in the operation in form of closely adherent adjacent structures to the spleen was encountered in $3(12.5 \%)$ patients. 7 (29.2\%) patients needed blood transfusion due to blood loss more than $400 \mathrm{ml}$. The mean morcellated specimen weight was $566.8 \pm 252.9 \mathrm{gm}$. Operative data are shown in Tables(4-6).

Table (4) : Operative data.

\begin{tabular}{|c|c|c|c|}
\hline Variable & $\begin{array}{c}\text { Operative time } \\
\text { (minutes) }\end{array}$ & $\begin{array}{c}\text { Intraoperative } \\
\text { Blood loss }(\mathrm{ml})\end{array}$ & $\begin{array}{c}\text { Specimen } \\
\text { weight }(\mathrm{gms})\end{array}$ \\
\hline Mean & 116.5 & 286.5 & 566.8 \\
\hline Std. deviation & 23.9 & 165.7 & 252.9 \\
\hline Minimum & 88 & 100 & 283 \\
\hline Maximum & 166 & 650 & 1260 \\
\hline
\end{tabular}

Table (5) : Operative data.

\begin{tabular}{|c|cc|cc|}
\hline Variable & \multicolumn{2}{|c|}{ Technical difficulty } & \multicolumn{2}{|c|}{ Conversion } \\
& Yes & No & Yes & No \\
\hline Frequency & 3 & 21 & 2 & 22 \\
\hline Percent & 12.5 & 87.5 & 8.3 & 91.7 \\
\hline
\end{tabular}

Table (6) : Operative data.

\begin{tabular}{|c|c|c|}
\hline $\begin{array}{c}\text { Amount } \\
\text { of transfusion } \\
\text { (units) }\end{array}$ & Frequency & Percent \\
\hline No & 17 & 70.8 \\
\hline 1 & 2 & 8.3 \\
\hline 2 & 3 & 12.5 \\
\hline 3 & 2 & 8.3 \\
\hline Total & 24 & 100 \\
\hline
\end{tabular}

The mean period until passage of flatus $2 \pm 1.1$ days. The patients resumed oral food intake in $3.2 \pm 1.4$ days and were discharged from the hospital in $4.6 \pm 1.9$ days. 4 patients $(16.7 \%)$ had post operative complications in their hospital stay, $3(12.5 \%)$ had wound infection (the midline incision) which was treated by dressing and antibiotics, and 1 (4.2\%) had prolonged ileus which was managed conservatively (all were converted cases). During the follow-up one patient (4.2\%) started to develop tachycardia and hypotension during the first postoperative day with bloody discharge more than $300 \mathrm{cc}$ in the drain with drop of serum $\mathrm{Hb}$. US was performed and confirmed the presence of hemoperitoneum. 
The patient was reexplored after resuscitation and bleeding from the short gastric vessels (sealed by Ligasure) was the cause, which was dealt with, and the patient then recovered smoothly. The patients were followed up for 3 months each and no complications were observed during the follow up. No mortality was recorded intra or post operatively. The postoperative data are shown in $\operatorname{Tables}(7,8,9)$.

Table (7): Postoperative data.

\begin{tabular}{|c|cc|cc|}
\hline \multirow{2}{*}{ Variable } & \multicolumn{2}{|c|}{ Reoperation } & \multicolumn{2}{c|}{ Complications } \\
& Yes & No & Yes & No \\
\hline Frequency & 1 & 23 & 4 & 20 \\
\hline Percent & 4.2 & 95.8 & 16.7 & 83.3 \\
\hline
\end{tabular}

Table (8): Postoperative data.

\begin{tabular}{|c|c|c|}
\hline Type of complication & Frequency & Percent \\
\hline None & 19 & 79.2 \\
\hline Wound infection & 3 & 12.5 \\
\hline Prolonged Ileus & 1 & 4.2 \\
\hline Postoperative bleeding & 1 & 4.2 \\
\hline Total & 24 & 100 \\
\hline
\end{tabular}

Table (9): Postoperative data.

\begin{tabular}{|c|c|c|c|}
\hline Variable & $\begin{array}{c}\text { Period of ileus } \\
\text { (days) }\end{array}$ & $\begin{array}{c}\text { Full oral intake } \\
\text { (days) }\end{array}$ & $\begin{array}{c}\text { Hospital stay } \\
\text { (days) }\end{array}$ \\
\hline Mean & 2 & 3.2 & 4.6 \\
Std. deviation & 1.1 & 1.4 & 1.9 \\
Minimum & 1 & 2 & 3 \\
Maximum & 5 & 6 & 9 \\
\hline
\end{tabular}

Potential predictive factors for conversion during laparoscopic splenectomy were thought to be the following: age, sex, diagnosis, comorbidities, ASA score, preoperative platelet count, preoperative hemoglobin, body mass index, splenic longitudinal axis length, presence of technical difficulty, and intraoperative blood loss. Univariate analysis of these factors was carried out and showed that significant risk factors for conversion were diagnosis, ASA score, presence of technical difficulty, preoperative platelet count, splenic longitudinal axis length, morcellated specimen weight, operative time, and intraoperative blood loss with $\mathrm{p}$ values less than 0.05 . Further analysis showed that morcellated specimen weight was dependent on the size of the spleen and operative time was dependent on spleen size and technical difficulty, so both were excluded from further analysis. There was no significant difference between completed and converted cases regarding their age, sex, presence of comorbidity, BMI and preoperative $\mathrm{Hb}$ values. The results of univariate analysis are shown in Tables(10,11). 
Table (10): Univariate analysis of risk factors for conversion of laparoscopic splenectomy.

\begin{tabular}{|c|c|c|c|c|c|}
\hline Variable & Conversion & N & Mean & Std. deviation & P-value \\
\hline Age & No & 20 & 26.1 & 9.1 & 0.640 \\
& Yes & 4 & 28.5 & 8.3 & \\
\hline Spleen Size & No & 20 & 15.0 & 2.0 & 0.000 \\
& Yes & 4 & 20.8 & 1.9 & \\
\hline BMI & No & 20 & 24.0 & 1.7 & 0.820 \\
& Yes & 4 & 23.8 & 3.1 & \\
\hline Preoperative Hb & No & 20 & 12.0 & 1.1 & 0.187 \\
& Yes & 4 & 13.0 & 1.7 & \\
\hline Preoperative platelet count (x1000) & No & 20 & 62.0 & 7.4 & 0.450 \\
& Yes & 4 & 71.3 & 10.7 & \\
\hline Operative time (minutes) & No & 20 & 109.8 & 19.8 & 0.001 \\
& Yes & 4 & 150.3 & 7.9 & \\
\hline Intraoperative blood loss (ml) & No & 20 & 224.8 & 93.6 & 0.000 \\
& Yes & 4 & 595.0 & 52.6 & \\
\hline Specimen weight (gms) & No & 20 & 499.4 & 183.0 & 0.002 \\
& Yes & 4 & 904.3 & 309.9 & \\
\hline Amount of transfusion (Units) & No & 20 & 0.2 & 0.5 & 0.000 \\
& Yes & 4 & 2.5 & 0.6 & \\
\hline
\end{tabular}

Table (11): Univariate analysis of risk factors for conversion of laparoscopic splenectomy.

\begin{tabular}{|c|c|c|c|c|}
\hline \multicolumn{2}{|c|}{ Variable } & Completed & Converted & P-value \\
\hline \multirow[t]{2}{*}{ Gender } & Female & 13 & 1 & \multirow[t]{2}{*}{0.178} \\
\hline & Male & 7 & 3 & \\
\hline \multirow[t]{4}{*}{ Diagnosis } & ITP & 13 & 0 & \multirow[t]{4}{*}{0.005} \\
\hline & Spherocytosis & 4 & 1 & \\
\hline & CLL & 1 & 3 & \\
\hline & Lymphoma & 2 & 0 & \\
\hline \multirow[t]{2}{*}{ Comorbidity } & $\mathrm{DM}$ & 3 & 1 & \multirow[t]{2}{*}{0.312} \\
\hline & None & 19 & 1 & \\
\hline \multirow[t]{2}{*}{ ASA score } & 2 & 20 & 0 & \multirow[t]{2}{*}{0.022} \\
\hline & 3 & 2 & 2 & \\
\hline \multirow[t]{2}{*}{ Technical Difficulty } & Yes & 2 & 2 & \multirow[t]{2}{*}{0.061} \\
\hline & No & 19 & 1 & \\
\hline \multirow[t]{2}{*}{ Need for transfusion } & Yes & 4 & 0 & \multirow[t]{2}{*}{0.003} \\
\hline & No & 17 & 3 & \\
\hline
\end{tabular}


Plotting of the ROC curve for assessment of intraoperative blood loss, preoperative platelet count and length of splenic longitudinal axis as predictors for the conversion of laparoscopic splenectomy was done and the results are shown in $\mathbf{T a b l e}(\mathbf{1 2})$.

Table (12): Intraoperative blood loss, preoperative platelet count and length of splenic longitudinal axis as predictors for the conversion.

\begin{tabular}{|c|c|c|c|c|}
\hline Variable & Cut-off value & Sensitivity & Specificity & AUC \\
\hline Intraoperative blood loss & $500 \mathrm{ml}$ & 1.000 & 1.000 & 1.000 \\
\hline Preoperative platelet count & $71 \times 10^{3} \mathrm{~cm}^{3}$ & 0.750 & 0.950 & 0.787 \\
\hline Length of splenic longitudinal axis & $17 \mathrm{~cm}$ & 1.000 & 0.900 & 0.975 \\
\hline
\end{tabular}

The assessment of the use of previous factors to predict the possibility of conversion revealed that intraoperative blood loss has a sensitivity of $100 \%$ and specificity of $100 \%$ when taking the level of $500 \mathrm{ml}$ as a cut-off value, and preoperative platelet count has a sensitivity of $75 \%$ and specificity of $95 \%$ when taking the level of $71 \times 10^{3} \mathrm{~cm}^{3}$ as a cut-off value, and length of splenic longitudinal axis has a sensitivity of $100 \%$ and specificity of $90 \%$ when taking the level of $17 \mathrm{~cm}$ as a cut-off value. This means that splenic longitudinal axis more than $17 \mathrm{~cm}$, preoperative platelet count less than $71 \times 10^{3} \mathrm{~cm}^{3}$ and intraoperative blood loss more than $500 \mathrm{ml}$ are predictors for conversion in laparoscopic splenectomy.

The significant risk factors (diagnosis, ASA score, presence of technical difficulty, preoperative platelet count, splenic longitudinal axis length and intraoperative blood loss) were included in multivariate analysis with a stepwise logistic regression model that showed that the significant independent predictive factor for conversion in this study group was the diagnosis of chronic lymphocytic leukemia (57 Odds Ratio and 95\% confidence interval 2.76 to $1176.83, \mathrm{P}=0.0024)$ and other significant factors from univariate analysis was dependent on it.

\section{Discussion:}

Since its introduction, laparoscopic splenectomy had become the golden standard for elective splenectomy, as it is feasible, safe and provides many advantages to the patients in comparison to open splenectomy, and the growing experience and the advances in equipment had made it feasible in situations that were thought to be contraindications in the past. 3,4

However the use of laparoscopic splenectomy in the treatment of splenomegaly and malignant disease is controversial and certain patients still require conversion to an open procedure. Identifying predictive factors for conversion carries benefits for patients and health care providers. From patients view, knowing this helps them identifying their postoperative course and potential complications. The health care providers can provide better equipment setup and more experienced surgeons for patients with risk factors for conversion, and the surgical team can better plan the procedure to suit patients' demands. $7-10$

Our study aimed to identify predictive risk factors for conversion to open splenectomy in patients undergoing elective laparoscopic splenectomy. Many authors had reported the impact of isolated factors on conversion, but only few ones had done a multivariate analysis for different factors leading to conversion. Our study reported a rate of conversion of $16.7 \%$ which is comparable to that published in the literature which range from $0-19 \% .{ }^{7}$ The cause of conversion in all patients was uncontrolled intraoperative bleeding, and this goes in line with cited literature which states that intraoperative bleeding is the most important direct cause for conversion. ${ }^{11}$ There was no significant difference in age, gender, BMI, preoperative $\mathrm{Hb}$ between completed and converted cases. This goes in line with literature except for BMI as it was reported that a patient 
with BMI more than 40 is a major risk for conversion in laparoscopic splenectomy, ${ }^{12}$ but our study didn't include patients with BMI more than 28 so this factor couldn't be assessed in the study group. This study had identified diagnosis, ASA score, presence of technical difficulty, preoperative platelet count, splenic longitudinal axis length, and estimated intraoperative blood loss as predictive factors for conversion. The diagnosis of CLL was the most important independent factor for conversion as it's associated with large spleen and technical difficulties as dense adhesions. This was also reported by Casaccia and his colleagues in their analysis of the Italian registry of laparoscopic surgery of the spleen in which they had reported that hematological malignancy is a significant risk factor for conversion. ${ }^{10} \mathrm{We}$ also had identified that the presence of technical difficulty as densly adherent adjacent structure is an important predictor for conversion and this was previously reported by Brody and his colleagues. ${ }^{7}$ In our study we identified that preoperative platelet count of less than $71 \times 10^{3} \mathrm{~cm}^{3}$ is major risk factor for conversion, this was partially reported in literature as Masayuki and his colleagues reported it as a risk factor for massive intraoperative bleeding and thus conversion in laparoscopic splenectomy, ${ }^{11}$ but they didn't specify a cutoff value. The size of the spleen (determined by splenic longitudinal axis length) was identified by our study as a main predictor for conversion with a cutoff value of $17 \mathrm{~cm}$. The presence of splenomegaly was identified by many authors as a predictor for operative difficulty and conversion with some referring to longitudinal axis length (greater than 16.5 $\mathrm{cm}$ ) and other referring to weight (more than $1000 \mathrm{gm}$ ) as a strong predictor for conversion. ${ }^{13-15}$ The surgeon's experience (learning curve) was reported as potential predictor for conversion ${ }^{9}$ but couldn't be assessed in our study because all cases were operated by one surgeon with good experience in these cases.

\section{Conclusion:}

The diagnosis of CLL, ASA score 3, presence of technical difficulty, preoperative platelet count $<71 \times 10^{3} \mathrm{~cm}^{3}$, splenic longitudinal axis length $>17 \mathrm{~cm}$ are important predictive factors for conversion of laparoscopic splenectomy to open procedure.

\section{References:}

1- Bell RA, Kate E, Reinhard T, Eugene C, John LF: A ten-year, single institution experience with laparoscopic splenectomy. Journal of the Society of Laparoendoscopic Surgeons 2005; 9: 163-168.

2- Delaitre B, Maignien B: Splenectomy by the laparoscopic approach. Report of a case (in French). Presse Med 1991; 20: 2263.

3- Habermalz B, Sauerland S, Decker G, Delaitre B, Gigot JF, Leandros E, Lechner $\mathrm{K}$, et al: Laparoscopic splenectomy: The clinical practice guidelines of the European Association for Endoscopic Surgery (EAES). Surg Endosc 2008; 22: 821-848.

4- Winslow ER, Brunt LM: Perioperative outcomes of laparoscopic versus open splenectomy: A meta-analysis with an emphasis on complications. Surgery 2003; 134: 647-653.

5- Glasgow RE, Mulvihill SJ: Laparoscopic splenectomy. World J Surg 1999; 23:3848.

6- Klingler PJ, Tsiotos GG, Glaser KS, Hinder RA: Laparoscopic splenectomy: Evolution and current status. Surg Laparosc Endosc 1999; 9:1-8.

7- Brody FJ, Chekan EG, Pappas TN, Eubanks WS: Conversion factors for laparoscopic splenectomy for immune thrombocytopenic purpura. Surg Endosc 1999; 13: 789-791.

8- Hashizume M, Tomikawa M, Akahoshi T, Tanoue K, Gotoh N, Konishi K, et al: Laparoscopic splenectomy for portal hypertension. Hepatogastroenterology 2002; 49: 847-852.

9- Nursal TZ, Ezer A, Belli S, Parlakgumus A, Caliskan K, Noyan T: Reaching proficiency in laparoscopic splenectomy. World J Gastroenterol 2009; 15(32): 40054008.

10-Casaccia M, Torelli P, Pasa A, Sormani MP, Rossi E: Putative predictive parameters for the outcome of laparoscopic splenectomy: A multicenter analysis performed on the Italian registry of laparoscopic surgery of the spleen. Ann of Surg 2010; 2: 287-291. 
11-Masayuki O, Takashi N, Toshifumi M, Rinshyun S, Atsushi S, Kohei S, Toshimitsu M, Seigo K: Analysis of risk factors for massive intraoperative bleeding during laparoscopic splenectomy. J Hepatobiliary Pancreat Surg 2005; 12: 433-437.

12-Edward PD, Yong UC, Scott BG, Alan M Y, Edward AG, John FS: Impact of morbid obesity on outcome of laparoscopic splenectomy. Surg Endosc 2007; 21: 422426.

13-Mahon D, Rhodes M: Laparoscopic splenectomy: Size matters. Ann R Coll Surg Engl 2003; 85: 248-251.
14-Targarona EM, Espert JJ, Cerdan G, Balague C, Piulachs J, Sugranes G, et al: Effect of spleen size on splenectomy outcome. A comparison of open and laparoscopic surgery. Surg Endosc 1999; 13: 559-562.

15-McAneny D, LaMorte WW, Scott TE, Weintraub LR, Beazley RM: Is splenectomy more dangerous for massive spleens? Am J Surg 1998; 175: 102-107. 